This is a peer-reviewed, accepted author manuscript of the following conference paper: Zou, T., Kaminski, M. L., Li, H., \& Tao, L. (2020). Projection and detection procedures for long-term wave climate change impact on fatigue damage of offshore floating structures. In Proceedings of the ASME 2020 39th International Conference on Ocean, Offshore and Arctic Engineering: Volume 2A: Structures, Safety, and Reliability [V02AT02A034] (Proceedings of the International Conference on Offshore Mechanics and Arctic Engineering - OMAE; Vol. 2A-2020). American Society of Mechanical Engineers(ASME). https://doi.org/10.1115/OMAE2020-18350

Proceedings of the ASME 2020

39th International Conference on Ocean, Offshore \& Arctic Engineering

OMAE 2020

June 28 - July 3, 2020, Diplomat Beach Resort, Fort Lauderdale, FL, USA

OMAE2020-18350

\title{
PROJECTION AND DETECTION PROCEDURES FOR LONG-TERM WAVE CLIMATE CHANGE IMPACT ON FATIGUE DAMAGE OF OFFSHORE FLOATING STRUCTURES
}

\author{
Tao Zou ${ }^{1}$, Miroslaw Lech Kaminski ${ }^{2}$,Hang Li ${ }^{1}$, Longbin $\mathrm{TaO}^{3}$ \\ 1Jiangsu University of Science and Technology, Zhenjiang City, China \\ ${ }^{2}$ Delft University of Technology, Delft, the Netherlands \\ ${ }^{3}$ Department of Naval Architecture, Ocean and Marine Engineering, University of Strathclyde, \\ Glasgow, UK
}

\section{ABSTRACT}

Fatigue damage is a cumulative process. The fatigue design of offshore structures requires long term wave data to calculate fatigue damage. However, the climate change may affect the long-term wave statistics and consequently affect the cumulative fatigue damage. This paper aims to project the trend of annual fatigue damage of offshore floating structures and to detect the climate change impact on the future fatigue damage by coupling a conventional fatigue design method with climate and wave models. Firstly, climate scenarios are selected to project the global radiative forcing level over decadal or century time scales. Secondly, climate models are used to simulate global or regional atmosphere circulations and to obtain the wind field data. Thirdly, wave conditions are simulated by coupling wind driven wave models to climate models. Fourthly, stress analysis and fatigue assessments are conducted to project the annual fatigue damage. At last, control simulations are carried out in order to identify the range of natural variability and to detect the human-induced change. A case study is presented for a Floating Production Storage and Offloading (FPSO) unit operating in the Sable field offshore South Africa. The results indicate that, in the Sable field, the significant wave height is considerably influenced by the human-induced climate change. However, when detecting its effect on the annual fatigue damage, this change induced by human activities is still partially masked by the dominant natural variability. In addition, both the significant wave height and the annual fatigue damage increase over century time-scales.

Keywords: climate models, wave models, natural climate change, human-induced climate change, fatigue damage

\section{INTRODUCTION}

Fatigue damage is a long-term cumulative process. The lifecycle of floating structures consists of design, manufacture, operation (service) and demolition stages. The whole lifecycle may last more than 30 years. As the climate change is also a long-term process, it is necessary to consider the climate change impact on waves and to estimate its effect on fatigue damage in the design stage. However, the conventional spectral approach of fatigue assessment for offshore floating structures is based on scatter diagrams [1]. The sea states in these scatter diagrams were basically measured in the past, and are assumed to be representative of the sea states in the future, ignoring the climate change impact.

The climate change impact on wave conditions has been widely investigated [2-4]. Most studies concentrated on the annual or seasonal variability of sea states, sea level rising and extreme sea states. However, the fatigue assessment requires wave scatter diagrams including the probability of occurrence of all short-term sea states [5], and the coexistence of wind waves and swells should also be considered[6]. In addition, the climate trend in the past is not necessarily representative of the climate trend in the future. In fact, the climate change rate varies year by year. The trajectory of climate change is very important to fatigue damage calculations, because all the short-term sea states contribute to the cumulative fatigue damage.

Climate change occurs as a result of both external forcing changes and internal variability within the climate system. The external forcing refers to the solar radiative forcing which is affected by the emission of greenhouse gases (GHGs). With the 
emission of GHGs, human activities are regarded with high confidence as the primary reason of climate change during the recent decades. Internal variability is caused by the different response time of climate components (atmosphere, ocean, land and sea ice) to external forcing [7]. Even without any change of external forcing, the internal variability may also occur naturally due to the non-linear interactions between the climate components. Therefore, externally induced climate change in this paper is also called human-induced climate change, and the internally induced climate change is called natural variability.

The modelling technology of the climate and ocean waves has been highly developed since last century. In 2008, the fifth phase of the Coupled Model Intercomparison Project (CMIP5) was proposed with the aim to examine climate "predictability" and to explore the ability of models to predict climate on decadal time-scales [8]. Twenty climate research groups around the world got involved in this project with different climate models and climate scenarios. In addition, wind-driven wave models are progressing into the third generation. These models, driven by wind forces, can numerically simulate wind-wave interactions, nonlinear wave-wave interactions, and energy dissipation [9]. The most widely used wind-driven wave models are Ocean Wave Model (WAM) [10], Simulating WAves Nearshore model (SWAN) [11], and WaveWatch-III model [12]. The application of these models has been demonstrated on various research fields $[5,13]$.

The methodology presented in this study aims to project the trend of annual fatigue damage and to detect the future fatigue damage of FPSOs. In the following sections, the methodology is introduced at first. A case study in the Sable oil field is followed to demonstrate the methodology. The Sable field is located offshore near South Africa, and the unique geographical location of the Sable field is vulnerable to waves from both the Atlantic and Indian Ocean. At last, the control simulations are conducted to identify the range of natural variability and detect the human induced climate change.

\section{METHODS}

The methodology has six steps, as outlined in Fig. 1. Firstly, the solar radiative forcing trajectories in the future are projected by the climate scenarios. Secondly, climate models are used to simulate global atmosphere and ocean circulations. Thirdly, wave conditions are numerically simulated by wind-driven wave models. Then, the stress analysis and fatigue damage in decadal time-scales are calculated with the projected wave scatter diagrams. Finally, the climate change trend is detected by control simulations.

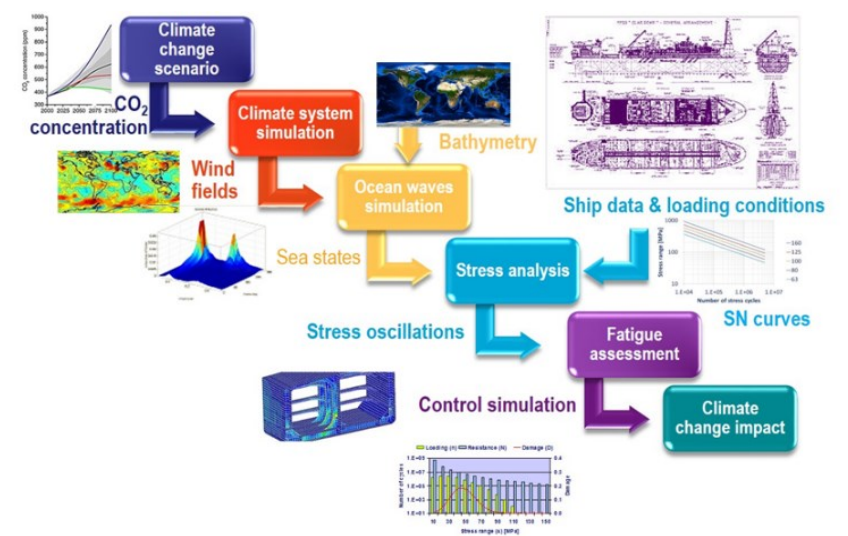

FIGURE 1: Outline of fatigue assessment method with allowance for climate change [5]

\subsection{Climate models}

Basically, most state-of-the-art climate models are constructed by the same fundamental physical laws (such as conservation of mass, energy and momentum) with many specific developments [7]. These models were designed for different purposes and may differ in parametrizations and numerical formulations. A climate model usually consists of four components: atmosphere, land surface, ocean and sea ice component models [1].

An atmosphere model, also called atmospheric general circulation model (AGCM), is numerically designed to simulate a wide range of key atmospheric processes, such as the exchanges of momentum, heat, water, and other tracers [15]. These processes are described by integrating a variety of dynamical, chemical, or even biological equations derived from the fundamental physical laws. There are various variables in the equations, including temperature, pressure and surface wind speed [16]. In atmosphere models, atmospheric momentum, heat and water are transferred both horizontally and vertically. Hence, all the atmosphere models are designed to have an adjustable horizontal resolution and multiple vertical layers. Most atmosphere models and ocean models are coupled to form an atmosphere-ocean coupled general circulation model (AOGCM), and the interactions between them are simulated. In this study, AOGCMs are the basis for a full climate model, because focus is given on the simulations of sea states.

The original driving force of climate system is solar radiative forcing. Due to the greenhouse effect, the emission of GHGs may affect the global distribution of radiative forcing and eventually cause climate change [16]. With the increase of GHGs concentration, the atmospheric layers absorb more longwave radiation from the ground surface and re-emit it back to the earth, which breaks the energy balance of the climate system [17].

Although GHGs are not the primary components of the atmosphere, they are very important for the climate change. In addition, their concentrations are highly affected by human activities, such as population growth, immigration, Gross Domestic Product (GDP), policy making, and energy 
consumption and composition [18]. In order to evaluate the climate change in the future, it is required to project all these factors and estimate their impact on the radiative forcing. As a result, plenty of different climate scenarios were presented, and it was hardly possible to compare one study to another. Therefore, in 2007, four climate scenarios named Representative Concentration Pathways (RCPs) were adopted in the Intergovernmental Panel on Climate Change (IPCC). RCPs project the emission of GHGs and the radiative forcing trajectory until the year 2100. Four RCPs are described and shown in Table 1 and Fig. 2, respectively [18]. When adopting RCPs, it is unnecessary to make specific assumptions related to population growth, economic development or other human related factors. It is possible that different human activities and environmental policies lead to the same radiative forcing level. RCPs enable researchers to neglect the specific human behaviors and to study the climate change impact directly. They provide information with the spatial resolution of approximately 60 kilometers and the temporal resolution of one year. The temporal resolution can be modified to monthly, daily or even 6-hourly by considering the seasonal cycle and the historic radiative data.

Table 1 The RCP descriptions

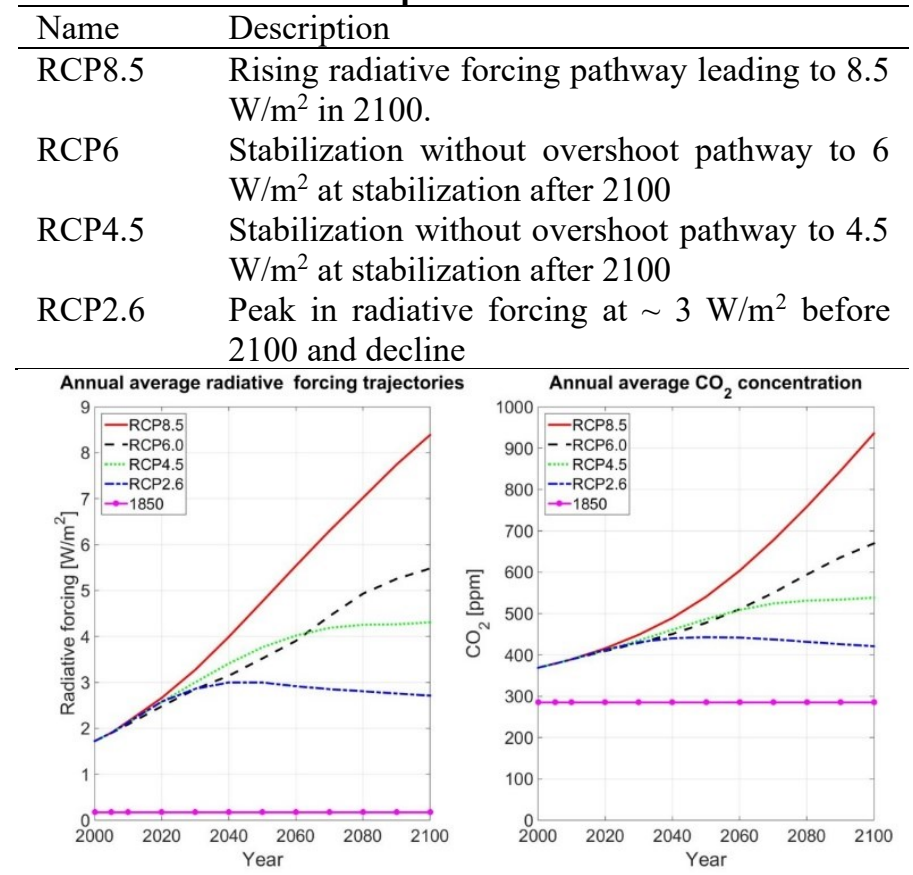

FIGURE 2: Outline of fatigue assessment method with allowance for climate change

In the CMIP5 project, the driving force of all the climate simulations is represented by the RCP radiative forcing trajectories. Therefore, the simulations by different climate models can be compared in order to evaluate the simulating ability of each climate model. Which RCP and climate model should be selected depends on the researchers' expectation of the future climate condition. All the simulation results are available online (http://cmip-pcmdi.llnl.gov/cmip5).

Theoretically, most climate change effects on the global atmosphere system can be simulated by climate models under the corresponding radiative forcing level. For example, the effect of climate change on the future surface wind fields can be simulated by projecting the radiative forcing trajectory instead of projecting wind fields directly. In addition, the radiative forcing level has a closer connection with human activities, and it is much easier to project the emission of GHGs rather than wind and waves in decadal time-scales. RCPs are not the real prediction of radiative forcing. Each RCP only stands for one expectation of the global radiative forcing trajectory and GHGs concentrations in the future. The climate projections are different from weather forecast, because weather forecast can be quickly tested. In contrast, there are no precise past analogues for the climate projections over time scales of many decades. The projected simulations of the future climate are the expected conditions corresponding to each RCP [7].

\subsection{Wind-driven wave models}

Wind-driven wave models are required to simulate ocean waves for fatigue assessment, because ocean waves are considered as the main source of fatigue damage for ships and offshore structures. The driving force of wave models is the surface wind field. Therefore, by coupling wave models to climate models, the future ocean waves are projected indirectly.

Wind-driven wave models are constructed based on energy or action conservations. They are designed to explicitly simulate the physical process of wave growth, wave propagation and wave dissipation on a large or even global scale. At a given sea location, there are two main types of ocean surface waves: wind waves and swells. Wind waves are generated by local winds at a considered location. Wind waves which have traveled to the considered location from remote locations are swells. In the wave models, both wind waves and swells are simulated and well partitioned for fatigue analysis. The sea state at each spatial grid point includes several wave systems (wind waves and swells). A wave spectral partitioning methodology with automated swell tracking and storm source identification capabilities is used in WaveWatch-III [19]. Each partitioned wave system is respectively represented by significant wave height, zerocrossing period and mean wave direction. More information on wind-driven wave models and their application to fatigue assessment can be found in Zou and Kaminski (2016) [5].

\subsection{Control simulations}

Climate change is a combination of the natural variability and the human-induced climate change. Natural variability has a high degree of randomness, while the effect of human activities on the climate trend is more deterministic. It is a challenge to separate human-induced climate change from observed or projected climate change. In other words, it is challenging to evaluate to what extent climate change is attributed to human activities. 
In climate models, natural variability is represented by simulating the nonlinear interactions and circulations of climate components under a certain radiative forcing level. For short term simulations, the initial conditions are also important for the randomness, because any small disturbance in the initial conditions may result in differences due to the nonlinear behaviors of climate model. With the increase of simulations period, the impact of initial conditions is becoming less pronounced. Therefore, a long term (decadal or century) control simulation with the controlled radiative forcing level is used to identify the randomness of natural variability. In control simulations, the radiative forcing is constant and equal to the mean forcing level of a preindustrial year (e.g., 1850). A longterm simulation is conducted under this constant radiative forcing by climate and wave models. As control simulations produce different responses of the climate system to the constant radiative forcing, the simulation time only represents the model time, not the real calendar years. The constant radiative forcing ensures that there is no human-induced climate change. If the simulations time is long enough, the range of natural variability can be identified.

In order to detect the human-induced climate change, the projected simulations under projected radiative forcing trajectories are compared with the control simulations. The result of projected simulations includes both human-induced climate change and natural variability. Once the projected climate trajectory exceeds the upper or lower limit of natural variability, the human-induced climate change is detected.

\section{CASE STUDY}

The case study of this methodology was conducted for the Glas Dowr FPSO at the Sable oil field, offshore South Africa $\left(35.21^{\circ} \mathrm{S}, 21.32^{\circ} \mathrm{E}\right)$. The main characteristics of the FPSO are presented in Table 2. The sea states of 2006-2020 and 2051-2060 were projected, and the annual fatigue damages were calculated based on the procedures shown in Fig. 1.

Table 2 Main characteristics of the Glas Dowr FPSO

\begin{tabular}{llll}
\hline Displacement & $\begin{array}{l}121,400 \\
\text { metric tons }\end{array}$ & Depth & $21.2 \mathrm{~m}$ \\
\hline Length & $232 \mathrm{~m}$ & Midship Draft & $12.99 \mathrm{~m}$ \\
\hline Breadth & $42 \mathrm{~m}$ & Water Depth & $103 \mathrm{~m}$ \\
\hline
\end{tabular}

\subsection{Climate change scenarios and wind field simulation}

In order to exemplify the effect of climate change, the climate scenario is defined as RCP8.5 which is characterized by increasing GHGs and radiative forcing level. According to RCP8.5, there are ten climate models available from CMIP5. Among them, ACCESS1.0, ACCESS1.3, CMCC-CM and MRI-CGCM3 are preliminarily selected, because they have finer grid resolutions, as listed in Table 3.

Table 3 The grid resolutions of climate models Model Name Atmospheric Grid Size

\begin{tabular}{lll}
\hline & Latitude & Longitude \\
\hline ACCESS1.0 & $1.25^{\circ}$ & $1.875^{\circ}$ \\
ACCESS1.3 & $1.25^{\circ}$ & $1.875^{\circ}$ \\
CMCC-CM & $0.75^{\circ}$ & $0.75^{\circ}$ \\
MRI-CGCM3 & $1.12^{\circ}$ & $1.125^{\circ}$ \\
\hline
\end{tabular}

The wind data simulated by these climate models were obtained from the CMIP5 database. The $10 \mathrm{~m}$ height annual wind speed from 2006 to 2015 was compared with ERA-interim dataset. In this paper, ERA-interim data are considered as the "true" data due to the lack of measured wind and wave data in the Sable field. ERA-Interim project is a global atmospheric reanalysis project covering the period from 1979 to the present [21]. This project can provide plenty of atmospheric data including $10 \mathrm{~m}$ height wind data with $1.0^{\circ} \times 1.0^{\circ}$ latitude/longitude grid and 6-hourly interval. It is using the wave model WAM to simulate the global waves with the same resolution [9].

To find the most suitable climate model in wind simulations, the averaged annual wind speed (the averaged value of annual wind speed) from all the climate models was compared with the ERA-interim dataset as shown in Table 4 and Fig. 3. The averaged wind speed and standard deviation $(S D)$ of these four climate models are all very close to ERA-interim. The maximum difference of wind velocity is $0.79 \mathrm{~m} / \mathrm{s}$ for MRI-CGCM3, and the minimum difference is $0.47 \mathrm{~m} / \mathrm{s}$ for ACCESS1.3. Compared with ERA-interim, each climate model tends to underestimate or overestimate continuously. CMCC$\mathrm{CM}$ is the only climate model which overestimated the wind speed for the decade. In contrast, the annual wind speeds of the other three models are always below ERA-interim. This result is consistent with the comparison of the cumulative probability distributions (Fig. 4). In addition, the wind speed distributions from ERA-interim and the climate models are compared by the quantile-quantile plot (Q-Q plot) (Fig. 5). The wind speed distributions of ACCESS1.0 and CMCC-CM are linearly related to the distribution of ERA-interim, because the points in the QQ plot are falling in a straight reference line (Fig. 5a and Fig. 5d). Similarly, most of the points in Fig. 5b and Fig. 5c also fall in a straight line, but they start to deviate from the straight line at high values. It indicates that the wind speed distributions of ACCESS1.3 and MRI-CGCM3 have a heavy or light right tail. In addition, the reference line (red) in Fig. $5 \mathrm{~d}$ is slightly steeper than the 45-degree straight line (black). Therefore, the CMCC$\mathrm{CM}$ distribution is more dispersed than the distribution of ERAinterim. Conversely, the distributions of the other climate models are less dispersed than ERA-interim. As mentioned above, all these climate models were designed for different spatial regions or research purposes. In this case study, wind data from CMCC$\mathrm{CM}$ are selected to drive the following wave simulations, because CMCC-CM has the finest grid resolution.

Table 4 The comparison of averaged annual wind speed from 2006 to 2015

$\begin{array}{cc}\begin{array}{c}\text { Wind velocity } \\ {[\mathrm{m} / \mathrm{s}]}\end{array} & S D \\ {[\mathrm{~m} / \mathrm{s}]}\end{array}$




\begin{tabular}{lll}
\hline ERA-Interim & 7.10 & 0.25 \\
ACCESS1.0 & 6.33 & 0.23 \\
ACCESS1.3 & 6.63 & 0.21 \\
CMCC-CM & 7.88 & 0.25 \\
MRI-CGCM3 & 6.31 & 0.28 \\
\hline
\end{tabular}

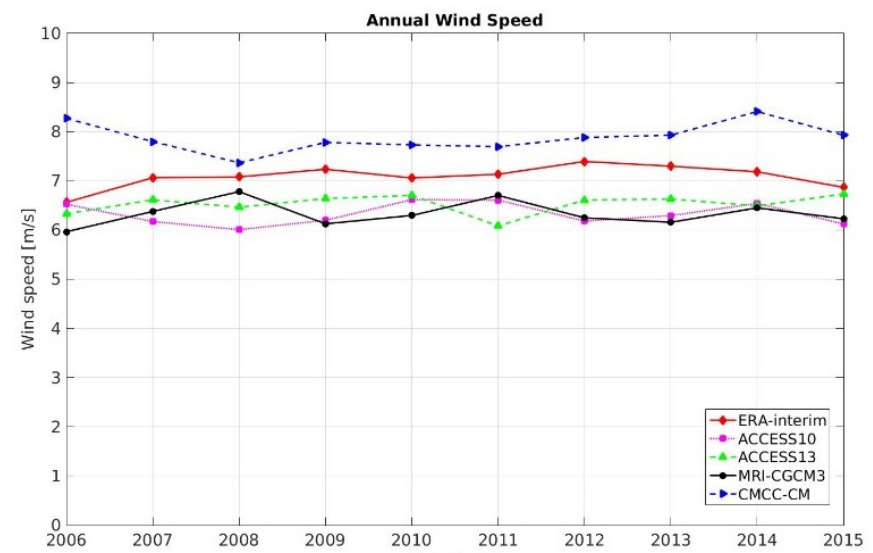

FIGURE 3: The comparison of annual wind speed from 2006 to 2015

Table 5 The modelling details

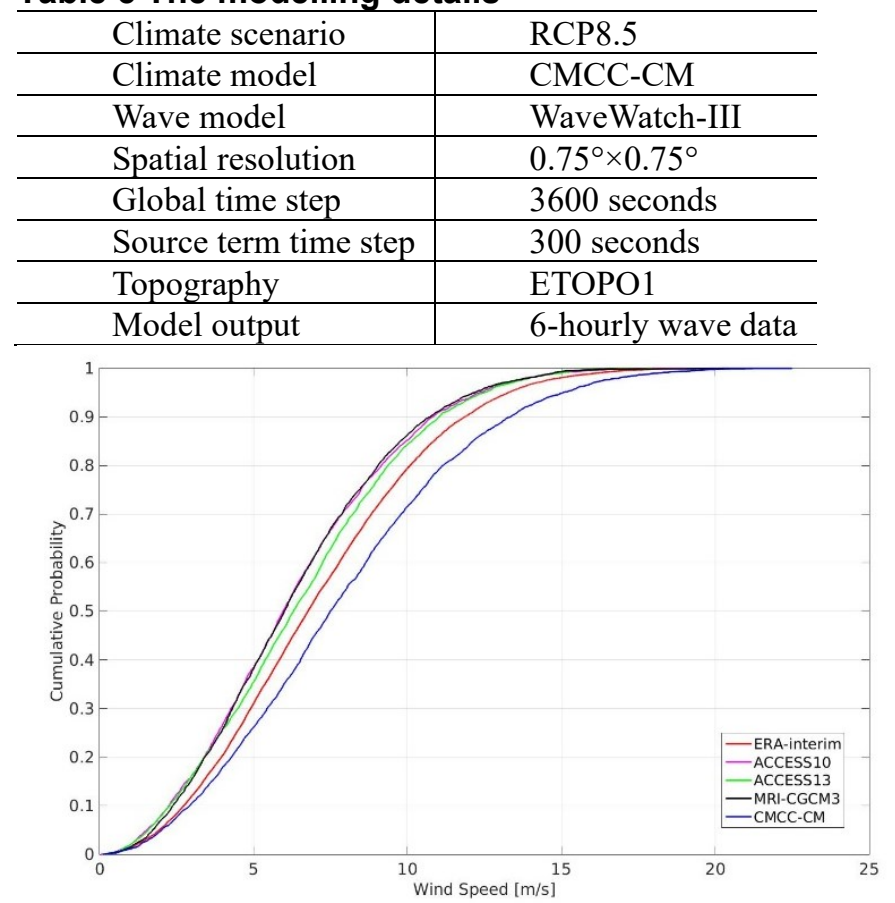

FIGURE 4: The cumulative probability of 6-hourly wind speed
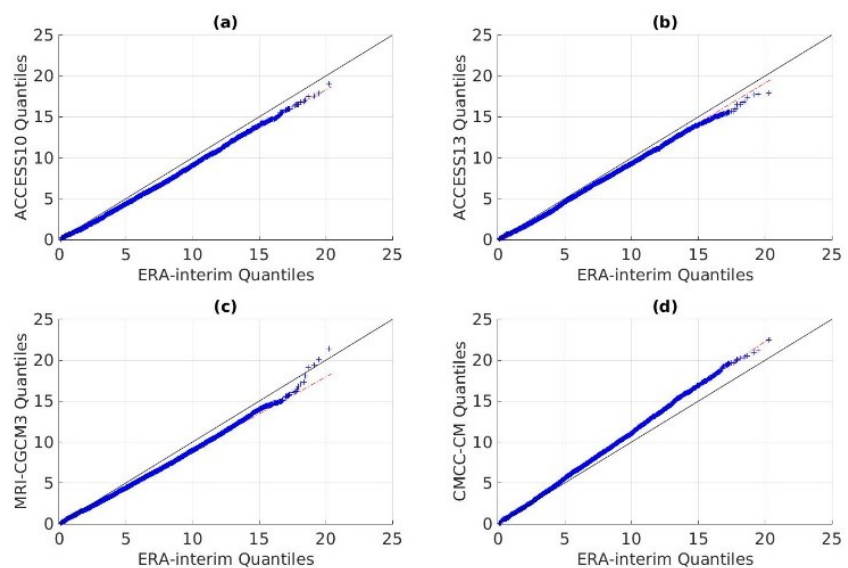

FIGURE 5: The Q-Q plot of wind speed data from ERAinterim and climate models

\subsection{Wave simulation}

WaveWatch-III was used to simulate ocean surface waves in this case study. WaveWatch-III is the third generation wave model developed at NOAA/NCEP [12]. A large scale or even global wave simulation is required to simulate all the waves in the Sable field, because the Sable field is located between the Atlantic and Indian Ocean. Global simulations can ensure that all the swells generated in remote sea areas could propagate into the Sable field. The output of the wave model is 6-hourly wave spectra defined for 24 directions (i.e. every $15^{\circ}$ ) and 25 frequencies ranging from $0.042 \mathrm{~Hz}$ to $0.414 \mathrm{~Hz}$. The spatial resolution of grids in the model is $0.75^{\circ} \times 0.75^{\circ}$ Latitude/ Longitude. The wave condition at each spatial grid point was partitioned into two wave systems (one wind wave and one swell). More details of modelling are listed in Table 5.

The FPSO is a turret moored vessel. Therefore, in order to receive proper structural response, the vessel heading should be calculated based on all the environmental loadings, such as wind, wave and current. In this case study, only wave loading was considered. The vessel heading was calculated in two steps. First, each wave system was represented by a vector. The mean wave direction $\theta_{m}$ of each vector is defined as the energy weighted mean direction over all frequencies [22]:

$$
\begin{aligned}
& \theta_{m}=\operatorname{atan}\left(\frac{b}{a}\right) \\
& a=\int_{0}^{2 \pi} \int_{0}^{\infty} \cos (\theta) F(\sigma, \theta) d \sigma d \theta \\
& b=\int_{0}^{2 \pi} \int_{0}^{\infty} \sin (\theta) F(\sigma, \theta) d \sigma d \theta
\end{aligned}
$$

where $F(\boldsymbol{\sigma}, \boldsymbol{\theta})$ is the wave spectral density. The length of each vector was proportional to the energy contained in each wave system. In the second step, the resultant vector was calculated as the geometrical sum of all wave system vectors. The vessel heading is just opposite to the direction of the resultant vector. Once the vessel heading is known, the relative wave directions $\alpha, \beta$, and $\gamma$ can be calculated. 
The sea states from 2006 to 2015 in the Sable field were simulated by WaveWatch-III. The results were compared with ERA-interim wave data as shown in Fig. 6. Table 6 lists the averaged significant wave height $\left(\overline{H_{S}}\right)$, standard deviation $(S D)$ and coefficient of variation (CV). The averaged significant wave height of CMCC-CM is $4 \%$ higher than the wave height of ERAinterim. The slight overestimate of wave height is consistent with the overestimate of wind speed by CMCC-CM.

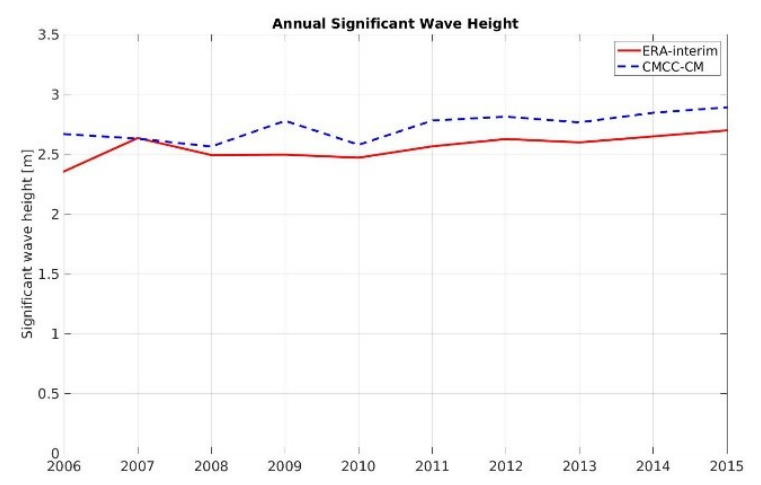

FIGURE 6: The comparison of annual significant wave height from 2006 to 2015

Table 6 Annual significant wave heights from 2006 to 2015

\begin{tabular}{llll}
\hline & $\overline{H_{s}}[\mathrm{~m}]$ & $S D[\mathrm{~m}]$ & $\mathrm{CV}$ \\
\hline CMCC-CM & 2.67 & 0.09 & 0.03 \\
ERA-interim & 2.56 & 0.10 & 0.04 \\
\hline
\end{tabular}

The wave conditions in the Sable field of 2011-2020 (present decade) and 2051-2060 (future decade) were projected with RCP8.5 to evaluate the impact of climate change. The gap between these two periods is 30 years, which is equal to the service lifetime of ships. The results are compared in Fig. 7 and Table 7. According to Fig. 7a, the averaged significant wave heights $\left(\overline{H_{s}}\right)$ of these two periods are very close to each other. Fig. $7 \mathrm{~b}$ and Fig. $7 \mathrm{c}$ show that $\overline{H_{s}}$ of future decade is neither continuously higher or lower than $\overline{H_{s}}$ of present decade. Hence, the averaged significant wave height is neither increasing nor decreasing continuously over time in the Sable field.

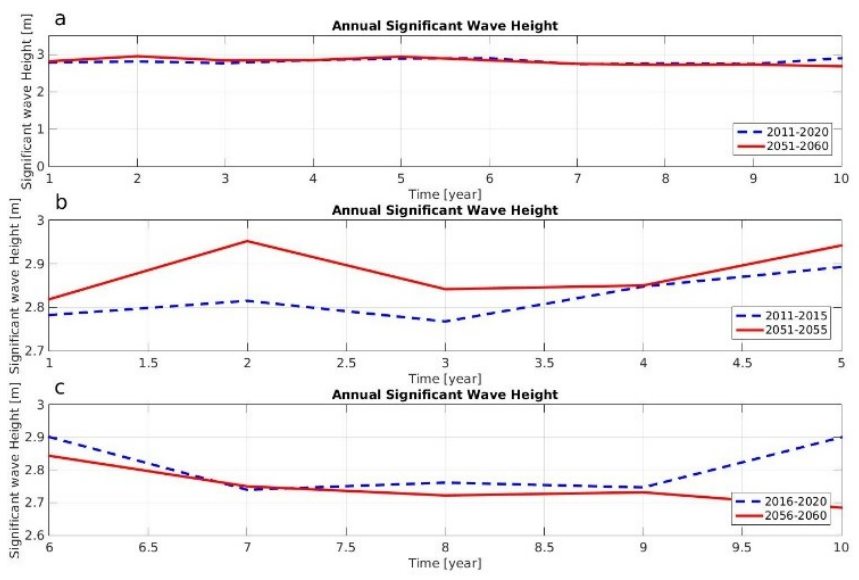

FIGURE 7: The comparison of annual significant wave height in 2011-2020 and 2051-2060. (b) and (c) are the zoomed-in plots of (a)

Table 7: Averaged annual significant wave heights in 2011-2020 and 2051-2060

\begin{tabular}{llll} 
& $\overline{H_{S}}[\mathrm{~m}]$ & $S D[\mathrm{~m}]$ & $\mathrm{CV}$ \\
\hline $2011-2020$ & 2.82 & 0.07 & 0.02 \\
$2051-2060$ & 2.81 & 0.09 & 0.03 \\
\hline
\end{tabular}

In order to evaluate the range of natural variability, a 30year control simulation was conducted under the constant radiative forcing level of the preindustrial year 1850. In 1850, the concentration of global GHGs was not significantly affected by human activities, and there was hardly any human-induced climate change. As a result, the time series of 43800 (30 years $\times 365$ days $\times 4$ sea states per day). continuous 6hourly sea states in Sable field was generated by CMCC-CM and WaveWatch-III.

All the 6-hourly sea states in the control simulation were subsampled by different sample sizes. Each sample size corresponds to one averaging period from 1 year to 10 years. For example, when the averaging period is 1 year, the sample size is 1460 (365 days $\times 4$ sea states per day). The sampling allows overlapping, but non-continuous sampling is precluded. In other words, all the neighboring sea states in each sample should not be interrupted in time, as shown in Fig. 8. Consequently, the sample size is $(30-1) * 365 * 4+1=42341$. When the averaging period is $n$ years, the sample size is $(30-$ n) years $\times 365$ days $\times 4$ sea states per day +1 . For each averaging period, the averaged significant wave heights of all samples were fitted by the normal distribution $N(\mu, S D)$ with mean value $\mu$ and standard deviation $S D$. Then, the confidence intervals of 0.05 and 0.95 for were defined as the lower and upper limits of natural variability for this averaging period. The sampling result of each averaging period is listed in Table 8 . The mean value of significant wave height for all the averaging periods is equal to $2.76 \mathrm{~m}$, because all the samples are from the same population (the 43800 continuous sea states from the control simulations). The samples with 1-year averaging period have the highest standard deviation, and the smallest $S D$ is for the samples with 10 -year averaging period. It means that the effect of natural variability is most significant for short-term averaged significant wave height. With the increase of averaging period, the effect of natural variability is becoming smaller. 
1 -year averaging period (Sample size: 42341)

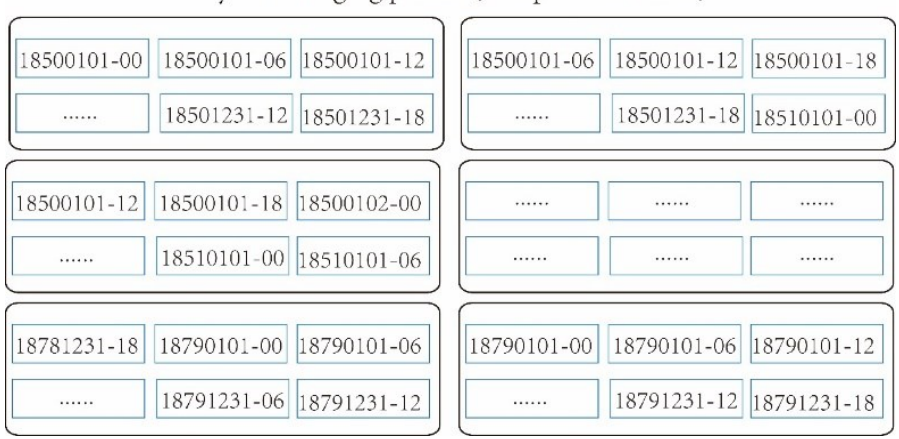

FIGURE 8: The illustration of sampling from the 30year control simulation. The sampling result for 1 -year averaging period is listed to exemplify the sampling approach. For the other averaging periods (from 2 years to 10 years), the results are not listed. The black boxes stand for the sampling units in each sample. Each sea state is represented in YYYYMMDD-HH format. The gap between neighboring sampling-units is 6 hours, as long as the length of one sea state. There are 42341 sampling units for 1 -year averaging period, which is also the number of sample size.

Table 8 The sampling result of each averaging period

\begin{tabular}{ccc}
\hline $\begin{array}{c}\text { Averaging period } \\
\text { [year] }\end{array}$ & $\mu[\mathrm{m}]$ & $S D[\mathrm{~m}]$ \\
\hline 1 & 2.76 & 0.097 \\
2 & 2.76 & 0.061 \\
3 & 2.76 & 0.045 \\
4 & 2.76 & 0.034 \\
5 & 2.76 & 0.027 \\
6 & 2.76 & 0.022 \\
7 & 2.76 & 0.022 \\
8 & 2.76 & 0.021 \\
9 & 2.76 & 0.019 \\
10 & 2.76 & 0.017 \\
\hline
\end{tabular}

In order to detect climate trend, the range of natural variability was compared with the projected significant wave height which was calculated based on simulations with RCP8.5 for the present decade 2011-2020 and the future decade 20512060 (Fig. 9). For the present decade, the averaged significant wave height $H_{s a}(t)$ in each averaging period $t=\{1 ; 2 ; \ldots ; 10\}$ was calculated as follows:

$$
\begin{aligned}
& H_{s a}(1)=\overline{H_{s a}}(2011) \\
& H_{s a}(2)=\overline{H_{s a}}(2011-2012) \\
& H_{s a}(3)=\overline{H_{s a}}(2011-2013) \\
& \vdots \\
& H_{s a}(10)=\overline{H_{s a}}(2011-2020)
\end{aligned}
$$

where $\overline{H_{s a}}(p)$ is the averaged significant wave height within the time period $p=\{2011 ; 2011-2012 ; 2011-$ $2013 ; \cdots ; 2011-2020\}$. For the future decade, the averaged significant wave height $H_{s a}(t)$ was calculated in the same way as in Eqs. (4)-(7).

It can be seen that when the sampling period is 1 year, the sampling data in the control simulations have the highest dispersion due to the natural variability. If the significant wave height of the 6-hourly sea states is a variable $H_{s} \sim N\left(\mu_{s}, \sigma_{s}\right)$. All the sea states are considered unrelated. For each averaging period, the number of sampled sea states is $N$, and their averaged significant wave height is defined as $\bar{H}_{s} \sim N\left(\bar{\mu}_{s}, \bar{\sigma}_{s}\right)$. $\mu_{s}$ is very close to $\bar{\mu}_{s}$, because they are from the same population. The standard deviation of $\bar{H}_{s}$ is the standard deviation of $H_{s}$ for each individual sea state divided by the square root of sea state number $\mathrm{N}$ :

$$
\bar{\sigma}_{S}=\frac{\sigma_{s}}{\sqrt{N}}
$$

$N$ is increasing with the length of averaging period. As a result, with the increase of averaging period, the dispersion of significant wave height is getting smaller and the range of natural variability is becoming narrower.

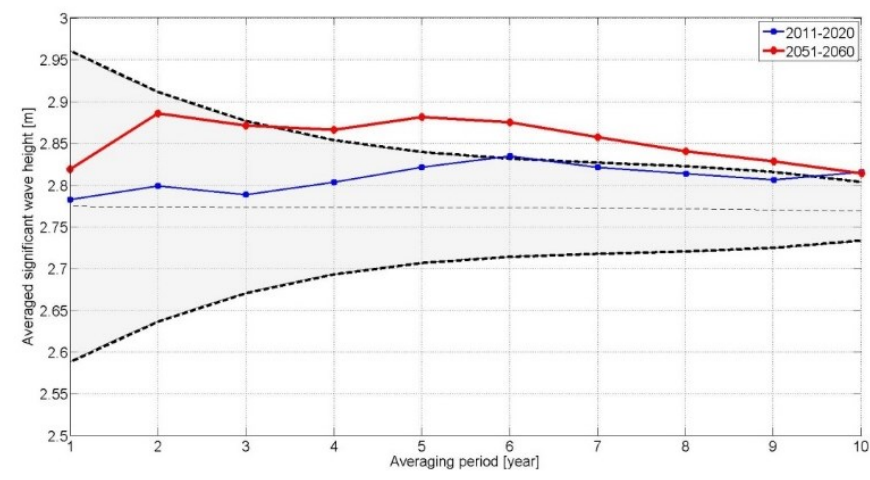

FIGURE 9: The natural variability of significant wave height and the detection of human-induced climate change. The shadowed area represents the range of natural variability calculated by the control simulation. The solid lines are the averaged significant wave heights for 2011-2020 (blue line) and for 2051-2060 (red line). They are calculated by projected simulations with RCP8.5. The horizontal straight dotted line is the averaged significant wave height in the control simulations for each averaging period (Table 8).

The human-induced climate change has been clearly detected, as the averaged significant wave heights in the present decade and the future decade (respectively, blue and red lines in Fig. 9 exceed the upper limit of natural variability. In addition, the averaged significant wave heights in these two periods are all above the straight dotted line. It means that human-induced climate change results in higher wave height in the Sable field over century time-scales. This conclusion contradicts earlier conclusion that averaged significant wave heights $\overline{H_{s}}$ in both periods 2011-2020 and 2061-2060 are close to each other (see Fig 9). A possible explanation is that the increased wave height in 2061-2060 induced by human activities is masked by the 
decreased wave height caused by the natural variability. Evidently, the selected periods 2011-2020 and 2051-2060 are too close to each other. The time gap is 30 years and is too short for exposing statistically significant trend of wave height change in the Sable field. The time gap should be probably at least 100 years for a statistically significant change of wave height. When the averaging period is 1 year, the averaged wave height of the present decade 2011-2020 is higher than the value of the future decade 2051-2060, because the significant wave height in 2051 is higher than in 2011. With the increase of averaging period, these two projections gradually converge, which is consistent with Table 8.

\subsection{Fatigue calculations}

Although increasing wave height caused by the humaninduced climate change has been detected, it does not mean that the same trend is valid for fatigue damage, because wave periods and wave directions also affect fatigue damage. The next step is to analyze stress range and calculate fatigue damage for FPSOGlas Dowr based on a hydro-structural linear model. Simple beam models were used to calculate the structural response. There are four loading mechanisms in this simple beam model: overall vertical and horizontal bending of the vessel, and local bending of secondary stiffeners caused by external action of waves and internal tank pressure fluctuations induced by varying motions of the FPSO. More information about stress analysis can be found in [5].

The fatigue damage at the main deck (Table 9) was calculated by Bluefat which is a component program of the advisory monitoring system Monitas [20,23]. By using the wave partitioning technique [19], the projected scatter diagrams of wave systems (wind wave and swells) for each year were constructed by wave simulations. Then, Bluefat calculated the wave-induced fatigue damage with the conventional spectral fatigue calculation method corrected for the intermittent wetting effect. The one-slope $\mathrm{S}-\mathrm{N}$ curve with $\mathrm{m}=3$ and $\log (\mathrm{C})=5.75$ (stress in $\mathrm{MPa}$ ) was used to represent the fatigue resistance.

Table 9 The location for fatigue calculations

\begin{tabular}{cccl}
\hline \multicolumn{3}{c}{ Position $[\mathrm{m}]$} & \multirow{2}{*}{ Description } \\
\cline { 1 - 3 } $\mathrm{x}$ & $\mathrm{y}$ & $\mathrm{z}$ & \\
112.85 & 18.3 & 21.31 & $\begin{array}{l}\text { On the main deck at frame 661/2 } \\
\text { above decks longitudinal \#22 [24] }\end{array}$ \\
\hline
\end{tabular}

No statistically significant trend of annual fatigue damage in both projected periods was detected as shown in Fig. 10. The averaged fatigue damages (the averaged value of annual fatigue damage within a certain period) in present decade 2011-2020 and future decade 2051-2060 are very close to each other, as listed in Table 10. The coefficient of variation for the annual fatigue damage (0.15 and 0.16) is much higher than the coefficient of variation for wave height $(0.02$ and 0.03$)$, because the fatigue damage is proportional to the third power of structural response when the inverse slope of S-N curves is equal to 3 . In the hydrostructural linear model, structural response is proportional to significant wave height, and the relation between unit wave height and structural response is represented by the linear transfer function. This result indicates that the annual fatigue damage has more variability than the annual significant wave height.

In order to validate the projected simulations, fatigue damage based on buoy-measurement was calculated for comparison. The sea state data in the Sable field were measured by buoys from July 2007 to June 2008 [25]. The fatigue damage in these 12 months was calculated as a reference value (Table 10). It is lower than the averaged fatigue damage in present decade and future decade. However, due to the existence of random natural variability, it does not mean that the methodology overestimates the annual fatigue damage. In fact, the projection of sea states for a particular year should not necessarily match buoy measurements due to both natural variability and the uncertainties in numerical models. The methodology is more useful to evaluate the trend of sea states and fatigue damage in a long-term period.

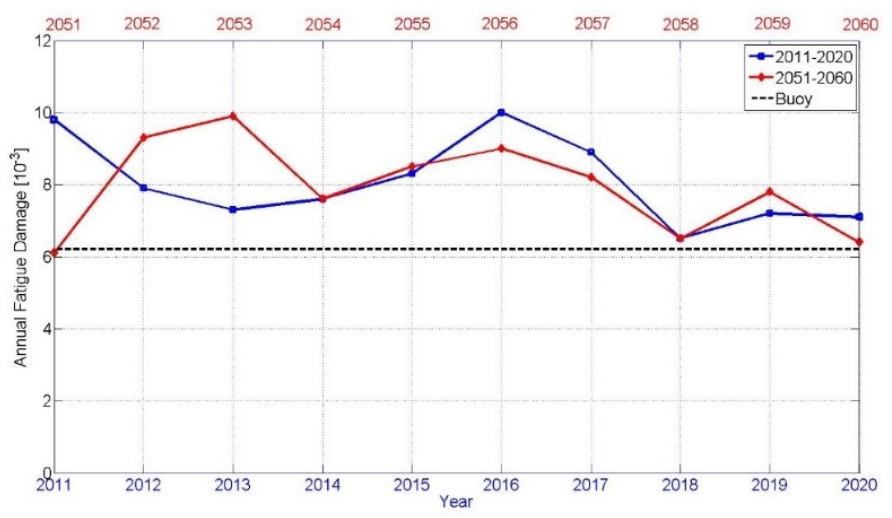

FIGURE 10: Projected annual fatigue damages in 20112020 and 2051-2060. The dotted straight line is the reference value of annual fatigue damage calculated based on the buoy-measurements in the period 07/2007-06/2008.

Table 10 Annual fatigue damages in 2011-2020 and 2051-2060

\begin{tabular}{llll}
\hline Period & $\begin{array}{l}\text { Averaged fatigue } \\
\text { damage }\left[\times 10^{-3}\right]\end{array}$ & $\begin{array}{l}S D \\
{\left[\times 10^{-3}\right]}\end{array}$ & $\mathrm{CV}$ \\
\hline $2011-2020$ & 8.06 & 1.18 & 0.15 \\
$2051-2060$ & 7.93 & 1.30 & 0.16 \\
$\begin{array}{l}\text { Buoy 07/2007- } \\
06 / 2008\end{array}$ & 6.20 & - & - \\
\hline
\end{tabular}

The effect of human-induced climate change on fatigue damage was also evaluated in the same way as its effect on wave height. Based on the result of the control simulation, the 30-year fatigue damage was calculated under the constant solar radiative level of 1850. The annual fatigue damages were subsampled with different averaging periods and fitted by normal distributions. The confidence intervals of 0.05 and 0.95 were defined as the lower and upper limits of natural variability for 
each averaging period. The range of natural variability was compared with the averaged fatigue damages of 2011-2020 and 2051-2060 in Fig. 11. The averaged fatigue damages were calculated in the similar way to the averaged significant wave heights as listed in Eqs. (4)-(7).

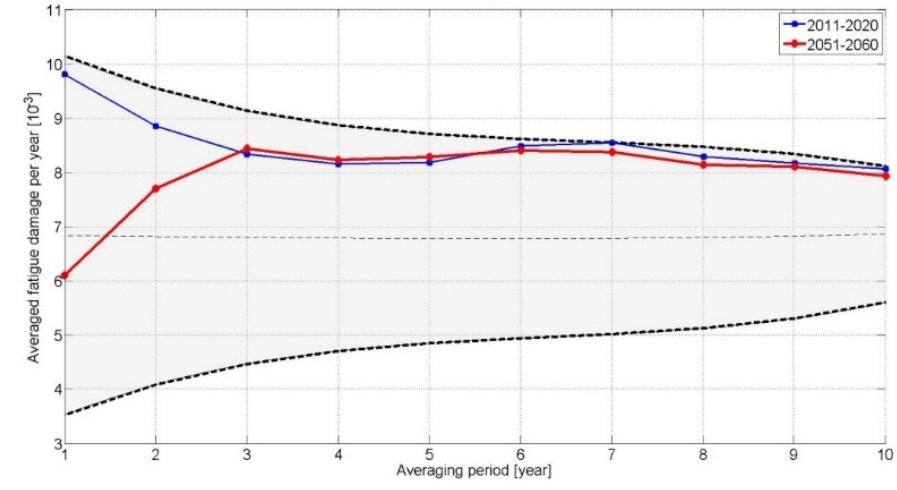

FIGURE 11: The natural variability of averaged annual fatigue damage and the detection of human-induced climate change. The shadowed area represents the range of natural variability calculated by the control simulation. The solid lines are the averaged fatigue damages from 2011 to 2020 (blue line) and from 2051 to $\mathbf{2 0 6 0}$ (red line). The horizontal straight dotted line is the averaged annual fatigue damage in the control simulations for each averaging period.

The annual fatigue damage in the Sable field is increased over century time-scales, because the projected fatigue damages are basically above the horizontal straight dotted line except for the annual fatigue damage in 2051 (the first point of red line in Fig. 11). This upward trend of fatigue damage is mainly attribute to the human-induced climate change, as the impact of human activities is slightly detected by the fatigue damage trajectory of the present decade (the blue line). However, the effect of humaninduced climate change on fatigue damage is not as pronounced as its effect on wave height. The exceedance of the fatigue damages over the upper limit is so small, and the annual fatigue damage is not increased significantly in the 30 years between the two projected periods. In other words, the upward trend of annual fatigue damage is not as significant as the trend of significant wave height, because fatigue damage is also affected by other factors, such as wave period, wave direction and the distribution of wave height. The annual fatigue damage in 2051 is relatively small, because the 1-year projected simulation in 2051 has a higher randomness and dispersion as explained in Eq. (8). Besides, the sea states in 2051 are more subjected to the influence of initial conditions, which can induce more randomness.

The effect of wave period change on fatigue damage is investigated below. In Fig. 12, the distributions of zero-crossing wave period for moderate and extreme sea states (significant wave height higher than $2.8 \mathrm{~m}$ ) in the projected and control simulations are compared. The mild sea states with significant wave height less than $2.8 \mathrm{~m}$ are dismissed due to their limited contribution to fatigue damage. The averaged wave period in the projected simulations is $10.13 \mathrm{~s}$, longer than the averaged period $(9.98 \mathrm{~s})$ in the control simulations. The longer wave period in the projected simulations indicates the lower frequency of cyclic wave loadings, which result in less fatigue damage. In contrast, according to the load transfer function of Glas Dowr (Fig. 13), the sea states with zero-crossing wave period of 10.13 s could induce greater structural responses and more fatigue damage than the sea states with $9.98 \mathrm{~s}$ wave period. Hence, although fatigue damage is very sensitive to wave height, the trend of significant wave height cannot fully represent the trend of annual fatigue damage. When analyzing the effect of climate change on fatigue assessment, the changes of other wave factors should also be taken into account.

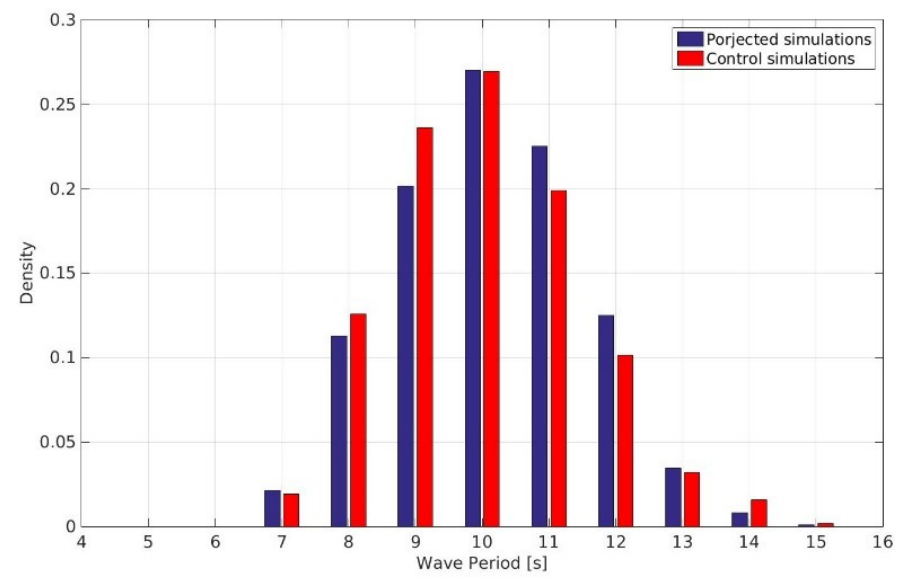

FIGURE 12: The distribution of zero-crossing wave period for moderate and extreme sea states (significant wave height higher than $2.8 \mathrm{~m}$ )

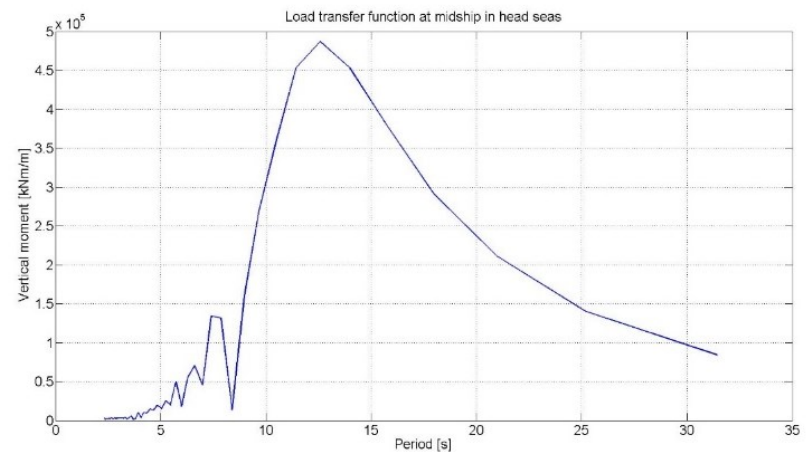

FIGURE 13: Load transfer function (Response amplitude operator) of midship in head seas for Glas Dowr 


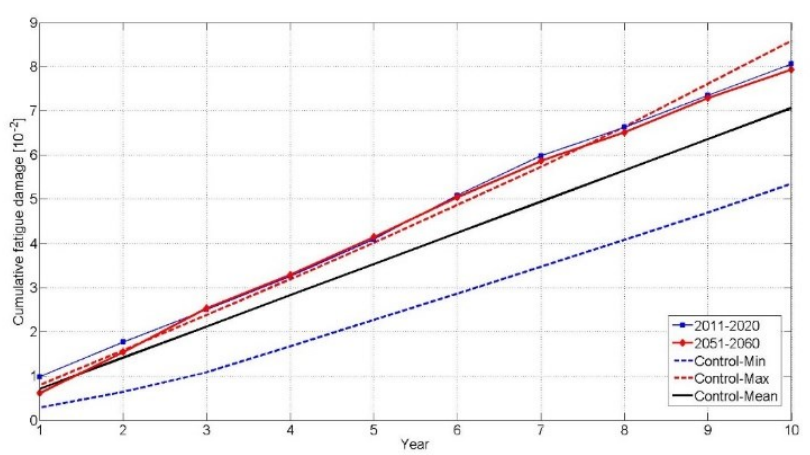

FIGURE 14: The comparison of cumulative fatigue damage. The Control-Max line is the cumulative fatigue damage based on the top 10 of annual fatigue damage in the 30-year control simulation. The ControlMin line is the cumulative fatigue damage based on the lowest 10 of annual fatigue damage in the control simulation. The Control-Mean black straight line is the cumulative fatigue damage based on the average annual fatigue damage of the control simulation.

The comparison of cumulative fatigue damage in Fig. 14 resulted in a similar conclusion to the comparison of annual fatigue damage above. The cumulative fatigue damages of 20112020 and 2051-2060 are both higher than the mean cumulative fatigue damage of the 30-year control simulations. In addition, they are very close to the maximum cumulative fatigue damage of the control simulation. It indicates that there is an increasing trend of fatigue damage over more than one century, but the upward trend of annual fatigue damage is not so significant due to the dominance of random natural variability.

\section{CONCLUSION}

The paper has presented a methodology to project the future fatigue damage of floating structures, and to detect the climate change impact on the future fatigue damage. The methodology has been applied for an FPSO moored in the Sable field, South Africa. The sea states and annual fatigue damages in the present decade 2011-2020 and the future decade 2051-2060 were projected based on RCP 8.5 , and the range of natural variability was estimated by the control simulations.

The effect of human-induced climate change on the significant wave height at the Sable field has been detected, and it has been found that the significant wave height considerably increases over a century. The effect of human-induced climate change on fatigue damage has been also detected. However, it is less pronounced, because fatigue damage is, besides wave height, also affected by other wave characteristics, such as wave periods and wave directionality. When investigating the effect of climate change on fatigue damage, the changes of all wave characteristics should be taken into account. In addition, it is concluded that the effect of natural variability is still dominant over human-induced climate change in the Sable field over decadal time-scales, and it partially counterbalances the impact of human activities on wave height and fatigue damage.
In general, the human-induced climate change is mixed with the natural climate variability. A control simulation allows for detection of such a change. Obviously, fatigue lifetime of offshore structures is highly dependent on the sea area and the structural properties. In this paper only one case has been presented in order to illustrate the application of the methodology. More cases in the other sea areas are being investigated.

\section{REFERENCES}

[1] DNV-GL-AS. Fatigue Assessment of Ship Structures 2014.

[2] Bitner-Gregersen EM, Horte T, Skjong R. Potential Impact of Climate Change on Tanker Design. Omae2011 Proc. Asme 30th Int. Conf. Ocean. Offshore Arct. Eng. Vol 2, 2011, p. 80513. doi:10.1115/omae2011-50162.

[3] Young IR, Zieger S, Babanin A V. Global trends in wind speed and wave height. Science (80- ) 2011;332:451-5. doi:10.1126/science.1197219.

[4] Vanem E, Bitner-Gregersen EM. Stochastic modelling of longterm trends in the wave climate and its potential impact on ship structural loads. Appl Ocean Res 2012;37:235-48. doi:10.1016/j.apor.2012.05.006.

[5] Zou T, Kaminski ML. Applicability of WaveWatch-III wave model to fatigue assessment of offshore floating structures. Ocean Dyn 2016;66:1099-108. doi:10.1007/s10236-0160977-4.

[6] ABS. Guide for Spectral-Based Fatigue Analysis for Floating, Production, Storage and Offloading (FPSO) Installations 2010.

[7] Solomon S, Qin D, Manning M, Chen Z, Marquis M, Averyt KB, et al. Climate Change 2007: The Physical Science Basis. Contribution of Working Group I to the Fourth Assessment Report of the Intergovernmental Panel on Climate Change. IPCC; 2007.

[8] Taylor KE, Stouffer RJ, Meehl GA. An Overview of CMIP5 and the Experiment Design. Bull Am Meteorol Soc 2012;93:485-98. doi:10.1175/bams-d-11-00094.1.

[9] Janssen PAEM. Progress in ocean wave forecasting. J Comput Phys 2008;227:3572-94. doi:10.1016/j.jcp.2007.04.029.

[10] Komen GJ, Cavalieri L, Donelan M, Hasselmann K, Hasselmann S, Janssen PAEM. Dynamics and Modelling of Ocean Waves. 1996.

[11] Booij N, Holthuijsen LH, Ris RC. The SWAN wave model for shallow water. Coast. Eng., vol. 1, Orlando, USA: 1996, p. 668-76. doi:https://doi.org/10.9753/icce.v25.\%25p.

[12] Tolman HL. the WAVEWATCH III Development Group (2014). User Manual and System Documentation of WAVEWATCH III version 4.18. Tech Note 316, NOAA/NWS/NCEP/MMAB 2014.

[13] Mentaschi L, Besio G, Cassola F, Mazzino A. Performance evaluation of Wavewatch III in the Mediterranean Sea. Ocean Model 2015;90:82-94. doi:10.1016/j.ocemod.2015.04.003.

[14] van Lieshout PS, den Besten JH, Kaminski ML. Comparative study of multiaxial fatigue methods applied to welded joints in 
marine structures. Fract Struct Integrity; No 37 July 2016DO 103221/IGF-ESIS3724 2016.

[15] Stocker T. Introduction to Climate Modelling. Springer-Verlag Berlin Heidelberg; 2011. doi:10.1007/978-3-642-00773-6.

[16] Wu T, Yu R, Zhang F. A Modified Dynamic Framework for the Atmospheric Spectral Model and Its Application. J Atmos Sci 2008;65:2235-53. doi:10.1175/2007jas2514.1.

[17] Introduction to Modern Climate Change. 2nd ed. Cambridge University Press; 2012.

[18] van Vuuren DP, Edmonds J, Kainuma M, Riahi K, Thomson A, Hibbard K, et al. The representative concentration pathways: an overview. Clim Change 2011;109:5. doi:10.1007/s10584011-0148-z.

[19] Hanson JL, Phillips OM. Automated Analysis of Ocean Surface Directional Wave Spectra. J Atmos Ocean Technol 2001;18:277-93. doi:10.1175/15200426(2001)018<0277:aaoosd >2.0.co;2.

[20] Aalberts P, van der Cammen J, Kaminski ML. The Monitas system for the Glas Dowr FPSO. Offshore Technol. Conf., Houston, Texas, USA: 2010.

[21] Berrisford P, Dee D, Poli P, Brugge R, Fielding K, Fuentes M, et al. The ERA-Interim archive [Version 2.0]. European Centre for Medium Range Weather Forecasts, Shinfield Park. Reading, Berksh RG2 9AX, United Kingdom 2011.

[22] Longuet-Higgins M, Cartwright DE, Smith ND. Observations of the directional spectrum of sea waves using the motions of a floating buoy. Ocean Wave Spectra, Proc. a Conf. Easton, Maryl., Prentice-Hall; 1963, p. 111-36. doi:citeulike-articleid:5675212.

[23] Kaminski ML., Aalberts P. Implementation of the Monitas system for FPSOs. Offshore Technol. Conf., Houston, Texas, USA: 2010.

[24] Kaminski ML. Sensing and understanding fatigue lifetime of new and converted FPSOs. Offshore Technol. Conf., Houston, Texas, USA: 2007.

[25] Hanson J, Ltibben A, Aalberts P, Kaminski ML. Wave Measurements for the Monitas System. Offshore Technol. Conf., Houston, Texas, USA: 2010. 